\title{
Enhancing an Extended Orientation Course Through the Use of Peer Instructors
}

\author{
Denise L. Rode and Christopher A. Kubic
}

The use of undergraduate paraprofessionals on college campuses has been recognized as an effective strategy for assisting new students in achieving academic and personal success. Astin (1993) indicated that "the peer group is the single most potent source of influence on growth and development during the undergraduate years" (p. 398). From an institutional standpoint, involving peer helpers has proved to be a cost-effective way of delivering important campus programs and services including tutoring, academic advising, and orientation. With this in mind, the Freshman Connections Program at Northern Illinois University decided to add a Peer Instructor (PI) component to its University Experience (UNIV 101) extended orientation course in the fall of 2000 .

\section{The Course}

UNIV 101 is a one-semester-hour, elective course intended to help first-year students make a successful transition to college life at NIU. Most sections of the course run for 12 weeks during the fall semester, although the sections for specially admitted students, who are required to enroll in the course, extend the full 16 weeks of the fall term. Course content includes designing strategies for academic success, becoming involved in college life, managing time and money, communicating with faculty, using university resources, and living in a diverse community. Sections are limited to 20-25 students and are taught by instructors who are recruited from the ranks of the tenured faculty and supportive professional staff who meet the qualifications for teaching the course (prior teaching experience at the college level and a master's degree). For Fall 2001, 1,350 students were enrolled in 68 sections taught by 59 instructors and assisted by 48 PIs.

\section{Adding a Peer Instructor Component}

With the course firmly established on the campus and well supported by the university's administration, the course coordinators in 1999 turned their attention to enhancing the UNIV 101 experience by introducing a PI component. Models of s uccessful programs on other campuses were considered before a plan was implemented. A professional position was added to the department's staff to develop the PI component and other desired program enhancements such as the creation of a customized text for the

Denise L. Rode is the Director of Orientation and Christopher A. Kubic is the Assistant Director of Orientation and Campus Information at Northern Illinois University. 
course.

\section{Recruiting Peer Instructors}

For the first year (Fall 2000), a goal of recruiting 30 PIs was set. Letters announcing the positions, accompanied by applications, were sent to scholarship recipients, honor society members, and other selected groups such as the Organization for Latin American Students and the Black Student Union. Applicants were required to have a minimum 2.5 grade point average with at least one semester completed at NIU at the time of application. Campus involvement was strongly recommended, as was prior experience as a UNIV 101 student. More than 80 applications were received for the 30 positions. Some applications were eliminated on review, but many brief interviews were conducted with the finalists until the desired group was determined. Most of those selected were completing their freshman year at NIU.

Instructors for the Fall 2000 semester were asked if they wished to have one or more PIs in their classrooms and if they could suggest former UNIV 101 students who would be effective Peer Instructors. Thirty-eight instructors responded that they wanted to teach with paraprofessionals; a total of 36 names were suggested for possible PI positions. In some cases, the instructor indicated a preference for working with a former UNIV 101 student, and these preferences were honored whenever schedules permitted.

The students suggested as Peer Instructors were contacted by mail to determine their interest in serving with the program. They were asked to complete and return a one-page application, after which a brief interview with a course coordinator and a graduate assistant or graduate student intern was held.

In the second year of the program (Fall 2001), recruitment was limited to asking instructors for recommendations and advertising in the campus newspaper. PIs were required to have taken UNIV 101 during their first year on campus. Forty-six PIs were selected and were matched with instructors based on when the PI was available. Near the end of the spring semester, a pizza party was held at a local restaurant, where in structors and PI.s could meet and begin to develop a positive working relationship. Some of the teams used that opportunity to begin planning the course for the fall semester.

Only one of the selected PIs could not be matched with a section due to schedule conflicts. In this case, the student was asked to serve as a member of the course advisory board and was guaranteed a PI position for the following year.

\section{Training and Incentives}

The PI position was designed as a volunteer paraprofessional role. Peer Instructors were expected to attend all class sessions and participate in a weekly planning meeting with the course instructor(s). They were also required to attend a brief training session at the start of the academic year. The session covered the following areas:

- $\quad$ an overview of the PI's responsibilities;

- $\quad$ an introduction to the textbook and other course materials; 
- tips for how to work most effectively with instructors;

- discussions about typical freshman concerns and how to help alleviate those fears; and

- advice from past PIs.

At the end of the semester, a reception was held to recognize all Freshman Connections instructors, mentors, and advisory board members. PIs are given NIU t-shirts at the reception and were personally thanked for their participation. In November 2001, a new annual award for the Outstanding Peer Instructor was given, which honored a graduating student who had served as a PI for three years and who had been instrumental in developing the program. Some PIs were eligible for internship credit through their major departments, which provided another incentive for participation.

\section{Lessons Learned}

Even in its first year, the PI component was deemed a success at NIU, and some of the lessons learned included:

- Currently enrolled students are eager to share their first-year experiences with those who follow them and to "give something back" to the university. Pis were easier than expected to recruit Peer Instructors for the volunteer positions;

- Instructors varied considerably in the ways in which they incorporated PIs in the UNIV classroom. Typical assignments include recording student attendance, offering "real life" examples of their experiences, organizing and presenting a class session, informing freshmen about campus events to encourage their participation, and arranging student panels to discuss current campus issues. PIs were not involved in determining students' grades, but often did comment on student papers and journals;

- PIs were received enthusiastically both by the course instructors and the freshman students;

- PIs served as important models for new students. By demonstrating a slightly higher level of student development, they provided a stimulus for new students to grow in understanding their responsibilities as college students;

- PIs bridged the gap between the course instructor and the first-year students, who often were inclined to approach a peer with an issue or concern before going to the instructor;

- The experience of serving as a PI can be an important role for upper division students, one which supports the development of self-confidence, connection with the college or university, and enhancement of skills such as public speaking, group facilitation, and time management. In a very short time, PIs have become recognized as providing significant service and leadership to the university. This enhances the student's credentials for future campus leadership positions, honors, and career pursuits; 
- For instructors, teaching with a PI did not necessarily lighten the work load. In fact, it often meant that instructors spent extra time planning with and supervising the PI;

- Implementing a PI component did not require a large budget. The cost of the NIU program was estimated at less than $\$ 1,500$ for the year, which included advertising, printed materials, t-shirts, training sessions, a pizza party, and the recognition reception.

Using peers to help deliver the NIU freshman course is seen as a "win-win-win-win" approach. New students win by learning from the experiences of someone who has recently "been in their shoes" and by having a role model of a successful NIU student to follow. Instructors win by having a student's realistic perspective in the classroom and by mentoring a PI through an unparalleled learning opportunity. The PI wins by developing valuable career and life skills and by serving in a quasi-professional role. And the university wins by increasing the power and effectiveness of the orientation course for freshmen while bringing PIs into a closer affiliation with the institution, thereby enhancing their retention and satisfaction with their college experience.

\section{Reference}

Astin, A.W. (1993). What matters in college? Four critical years revisited. San Francisco: Jossey-Bass. 